\title{
DURABILITY OF BASALT FIBERS IN CONCRETE MEDIUM
}

\author{
HIMABINDU MYADARABOINA, DAVID LAW, and INDUBHUSHAN PATNAIKUNI \\ School of Civil Environmental and Chemical Engineering, RMIT University, Melbourne, \\ Australia
}

This study investigates the durability of basalt fiber following immersion in a range of chemical solutions representative of the concrete medium. The tests were conducted over a 62-day period and the solutions were sodium hydroxide, sodium chloride, sodium sulfate and combinations of the three. Weight loss was observed in all alkali solutions, with the worst being the combination of sodium hydroxide with sodium sulfate. The impact of chloride was minimal in the alkaline environment and reduced the impact of the sulfate when both were present. Microstructure analysis using a Scanning Electron Microscope (SEM) found that the silica structure present in basalt fibers was degraded by the $\mathrm{OH}$ - from an alkaline medium. The study suggests the need for modification or treatment of basalt fibers before use as fiber reinforcement in concrete.

Keywords: Basalt fiber, Chemical durability, Concrete, SEM, Fiber reinforcement.

\section{INTRODUCTION}

The high fire resistance and low price of basalt fiber (BF), compared to traditional fibers, has led to the emergence of $\mathrm{BF}$ as an attractive alternative to other fibers in fiberreinforced polymer composites (FRP) in civil engineering in recent years. FRP has been successfully used for strengthening, rehabilitation and renewal of civil structures for over the last two decades (Jongsung et al. 2005).

More recently, continuous fibers extruded from naturally fire-resistant basalt (at temperatures $1300^{\circ} \mathrm{C}-1400^{\circ} \mathrm{C}$ ) have been investigated as a replacement for asbestos fibers in almost all of its applications. The wide temperature range $\left(-260^{\circ} \mathrm{C} /-2000^{\circ} \mathrm{C}\right.$ to about $\left.650^{\circ} \mathrm{C} / 8000^{\circ} \mathrm{C}\right)$, compared to $\mathrm{E}$ glass $\left(-600^{\circ} \mathrm{C}\right.$ to $\left.450^{\circ} \mathrm{C} / 4600^{\circ} \mathrm{C}\right)$, enables the $\mathrm{BF}$ to good enough insulators to replace asbestos (Van de Velde 2001).

There has been little previous research on the chemical stability of BF. Some shortterm studies reported that the alkali resistance of BF is good (Militky 2003, Wang 2008). But more recently studies have reported the chemical degradation of BF in alkaline environments (Bin 2011, Rabinovich 2011, Bo et al. 2010, and Jung et al. 1994).

The present study confirms the degradation of $\mathrm{BF}$ in alkaline environments, carrying out a detailed study with comparatively long-term analysis on chemicals, as well as micro-structural analysis under a Scanning Electron Microscope (SEM). 


\section{RESEARCH SIGNIFICANCE AND METHODOLOGY}

Given that concrete is highly alkaline, the use of BF as FRP in concrete is of great concern for long-term durability and performance of BF in concrete. A range of other potentially deleterious chemicals may also be present, the most common chloride ions from marine environments and de-icing salts, together with sulfate ions from the soil and groundwater. This study investigated the durability of BF in an alkali medium, as well as alkali combined with sulfate and/or chloride ions, representing aggressive environments in concrete. Hence, strong alkali such as $\mathrm{NaOH}$ and salts of strong alkali and base $\left(\mathrm{NaCl}\right.$ and $\left.\mathrm{Na}_{2} \mathrm{SO}_{4}\right)$ are considered for this study.

The effect on durability is measured by calculating the weight loss after soaking fibers in different solutions over a period of 62 days. The condition of the fibers is also examined visually and using SEM on FEI Quanta 200 ESEM.

\section{MATERIALS}

\subsection{Basalt Fibers}

The nominal diameters of these continuous filaments ranged between 9 to $24 \mu \mathrm{m}$. Figure 1 shows the BF used in this project along with its SEM image. The basalt fiber used in this experiment was provided by Kemenny Vek Ltd., Dubna, Moscow, Russia.

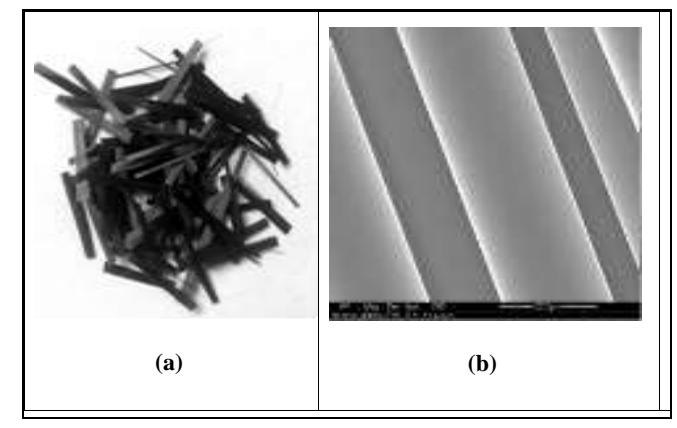

Figure 1. (a) Original BF and (b) SEM image of BF at $4 \mathrm{~K}$.

\subsection{Chemical Solutions}

Six different chemical solutions were prepared. These were selected to simulate the alkaline cementitious matrix. $1 \mathrm{M} \mathrm{NaOH}$ represented the alkaline nature of concrete, $3 \% \mathrm{NaCl}$ represented the contamination by chloride ions, $10 \% \mathrm{Na}_{2} \mathrm{SO}_{4}$ represented the contamination by sulfate ions, and their three combinations simulated the effect of both chlorides and sulfates. The strengths of the solutions were selected to provide accelerated testing regime.

\section{EXPERIMENTAL PROCEDURE}

For the experiment, samples were prepared by placing $45 \mathrm{~g}$ of BF in $500 \mathrm{ml}$ of each solution. The weight of BF was measured at fixed intervals at 3, 7, 14, 21, 28, 42 and 62 days. The $\mathrm{pH}$ of the solutions was also measured at each time interval. The BF measurements were taken by washing the specimens with distilled water and placing 
them in an oven for $24 \mathrm{hrs}$ at $105^{\circ} \mathrm{C}$ to obtain a dry mass at each time interval. A photographic record of the fiber was also made at each point and fig 3 shows the images after the treatment period of 62 days.

Prior to the conclusion of the experiment, the specimens were also analysed using SEM technique to determine the condition of the fibers after and before the treatment, and the presence of any precipitates on the fibers.

\section{RESULTS AND DISCUSSION}

The mass of $\mathrm{BF}$ with time in each solution along with \% weight lost and $\mathrm{pH}$ at the conclusion of the tests is given shown in Table 1 and Figure 2.

Table 1. Results obtained from the experiment during 62 days.

\begin{tabular}{|c|c|c|c|c|c|c|}
\hline & $\begin{array}{c}\mathrm{BF} \\
\text { in } \\
\mathrm{NaCl} \\
\end{array}$ & $\begin{array}{r}\mathrm{BF} \text { in } \\
\mathrm{Na}_{2} \mathrm{SO}_{4} \\
\end{array}$ & $\begin{array}{l}\mathrm{BF} \text { in } \\
\mathrm{NaOH}\end{array}$ & $\begin{array}{c}\mathrm{BF} \text { in } \\
\mathrm{NaOH}+\mathrm{NaCl}\end{array}$ & $\begin{array}{c}\mathrm{BF} \text { in } \\
\mathrm{NaOH}+\mathrm{Na}_{2} \mathrm{SO}_{4}\end{array}$ & $\begin{array}{c}\mathrm{BF} \text { in } \\
\mathrm{NaOH}+\mathrm{NaCl}+\mathrm{Na}_{2} \mathrm{SO}_{4}\end{array}$ \\
\hline Day 0 & 45.00 & 45.00 & 45.00 & 45.00 & 45.00 & 45.00 \\
\hline Day 3 & 45.96 & 46.05 & 45.65 & 45.50 & 46.40 & 46.80 \\
\hline Day 7 & 45.49 & 45.55 & 44.50 & 44.65 & 43.30 & 44.80 \\
\hline Day 15 & 44.66 & 44.70 & 41.85 & 41.60 & 39.10 & 38.95 \\
\hline Day 21 & 44.76 & 44.80 & 39.80 & 40.25 & 35.80 & 36.85 \\
\hline Day 28 & 44.39 & 44.45 & 37.50 & 38.80 & 30.65 & 34.45 \\
\hline Day 42 & 44.22 & 44.35 & 35.90 & 36.70 & 14.90 & 30.25 \\
\hline Day 62 & 44.13 & 44.15 & 31.85 & 32.50 & 3.90 & 27.00 \\
\hline $\begin{array}{l}\text { Original } \mathrm{pH} \\
\text { of the } \\
\text { solution }\end{array}$ & 9.22 & 9.22 & 12.22 & 12.8 & 12.90 & 13.35 \\
\hline $\begin{array}{l}\mathrm{pH} \text { after } 62 \\
\text { days } \\
\% \text { of Weight }\end{array}$ & 8.33 & 8.19 & 12.55 & 12.68 & 12.93 & 12.83 \\
\hline $\begin{array}{l}\text { Loss of BF } \\
\text { after } 62 \text { days }\end{array}$ & 1.89 & 1.87 & 29.2 & 34.7 & 90 & 37.8 \\
\hline
\end{tabular}

\subsection{Visual Analysis}

The following observations are made based on the visual analysis made on Figure 3:

- No surface damage was observed in the $\mathrm{BF}$ treated with $\mathrm{NaCl}$ and $\mathrm{Na}_{2} \mathrm{SO}_{4}$. The condition of the fibers at the conclusion of the test appeared same as the original BF, Figure 3-a. At the conclusion of the test there was only a $1.89 \%$ variation in the initial and final weight, Table 1.

- Severe damage of the fibers was observed in the BF treated with $\mathrm{NaOH}$, $\mathrm{NaOH}+\mathrm{NaCl}$ and with $\mathrm{NaOH}+\mathrm{NaCl}+\mathrm{Na}_{2} \mathrm{SO}_{4}$. The fibers had lost all of its 
original characteristics such as colour and texture and each fiber had broken and split into many thin strands.

- Whereas complete dissolution of the fibers was observed in the BF treated with $\mathrm{NaOH}+\mathrm{Na}_{2} \mathrm{SO}_{4}$. Not only had the fibers lost all of their original colour and texture, but most of the fibers had become powder, Figure 3-e. The weight loss observed was around $90 \%$ at the end of 62 days, Table 1.

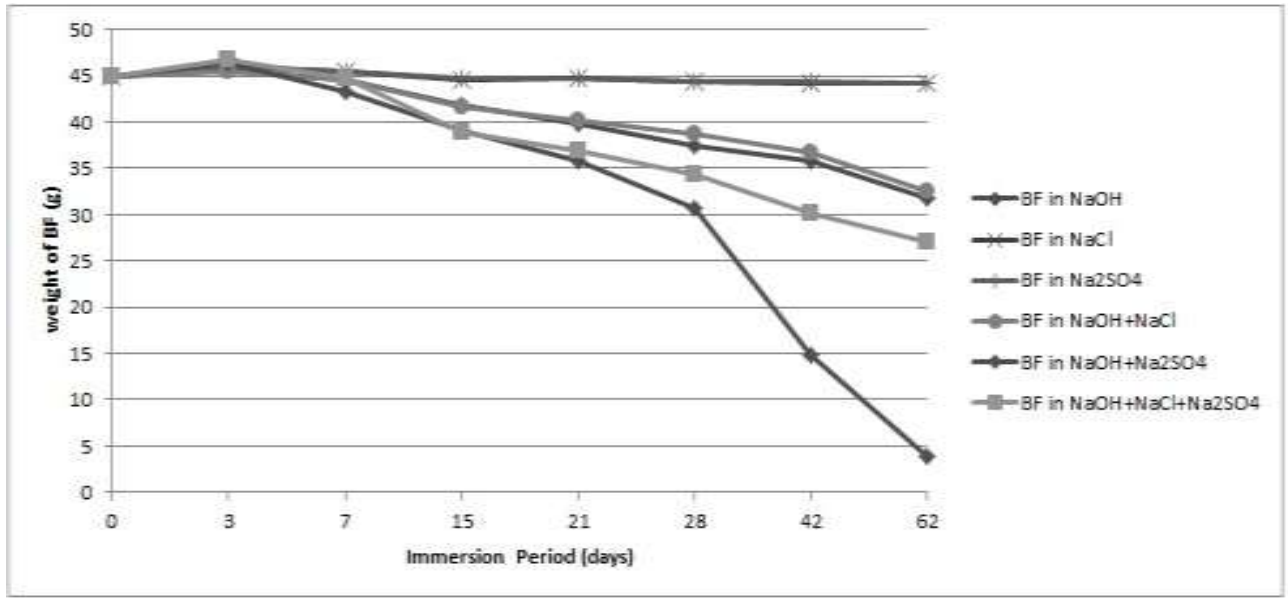

Figure 2. Weight loss of the BF immersed in different solutions vs. time over 62 days.

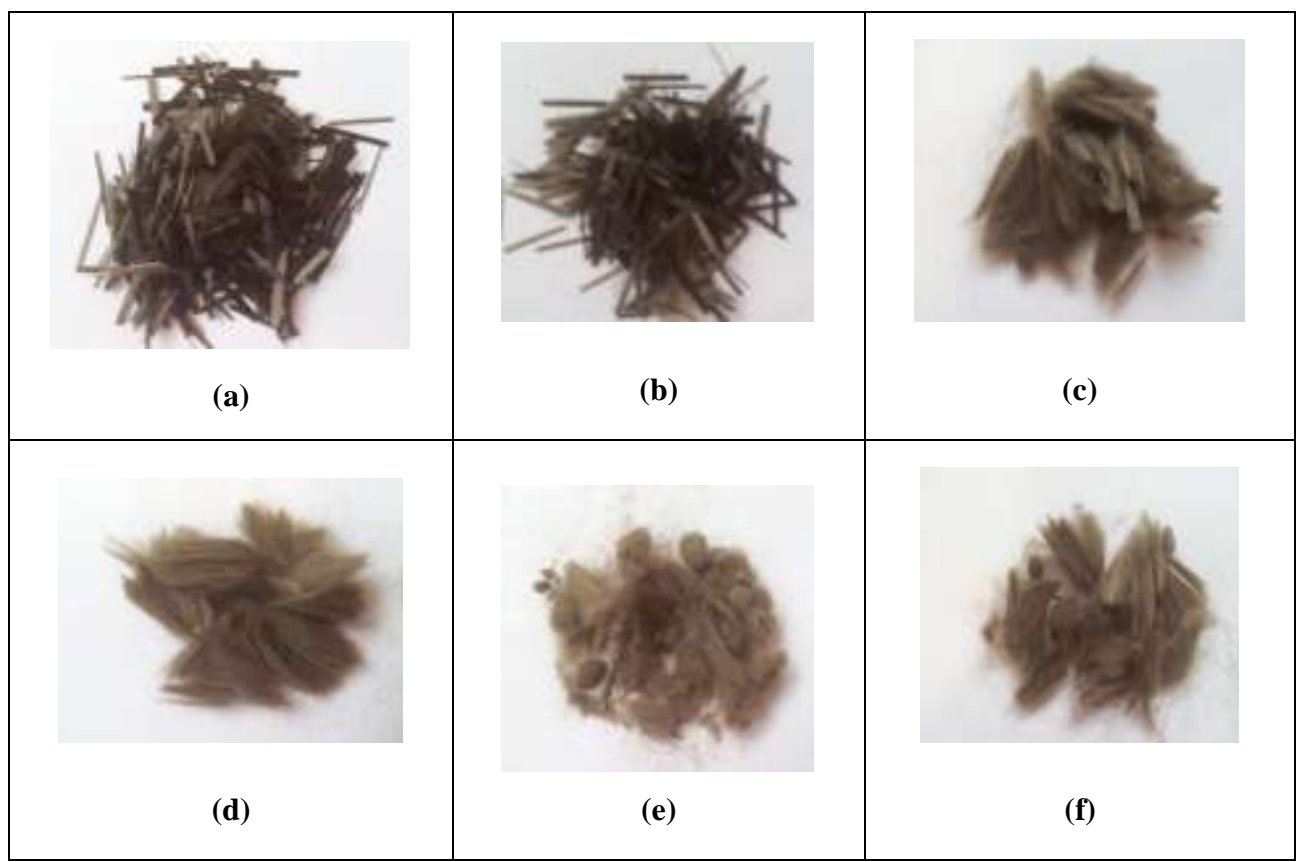

Figure 3. BF after 62 days of treatment with a) $3 \% \mathrm{NaCl}$ (b) $10 \% \mathrm{Na}_{2} \mathrm{SO}_{4}$ (c) $\left.1 \mathrm{M} \mathrm{NaOH} \mathrm{d}\right) 1 \mathrm{M}$ $\mathrm{NaOH}+3 \% \mathrm{NaCl}$ e) $1 \mathrm{M} \mathrm{NaOH}+10 \% \mathrm{Na}_{2} \mathrm{SO}_{4}$ (f) $1 \mathrm{M} \mathrm{NaOH}+10 \% \mathrm{Na}_{2} \mathrm{SO}_{4}+3 \% \mathrm{NaCl}$. 


\subsection{SEM Analysis}

The basalt fibers were examined using SEM analysis to determine changes in the morphology and composition with time. An analysis was conducted on untreated fibers at day 0 and on fibers from each solution at the conclusion of the trial. The SEM images and \% chemical compositions of each specimen are given in Figure 4.

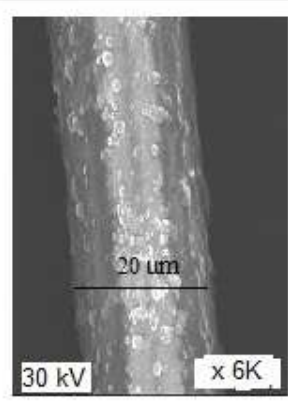

(a)

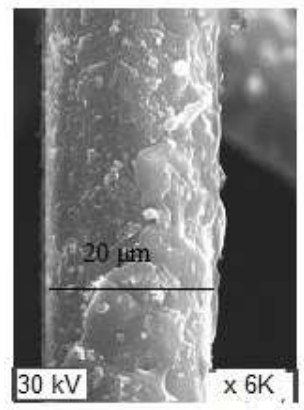

(d)

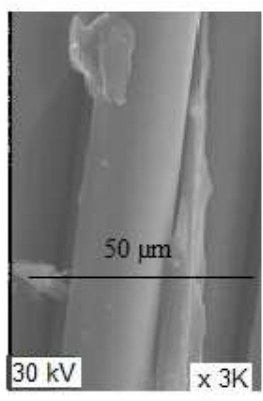

(b)

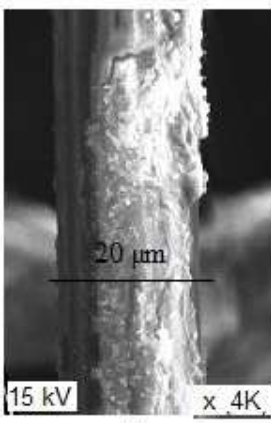

(e)

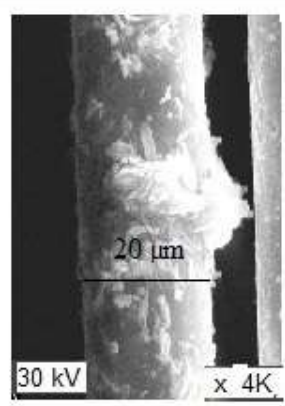

(c)

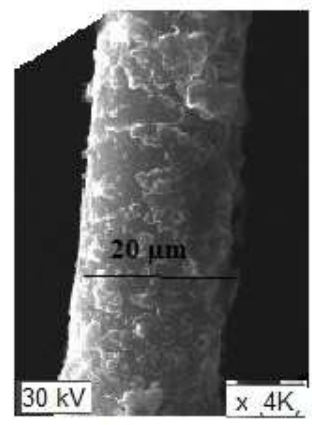

(f)

Figure 4. SEM images of $\mathrm{BF}$ after 62 days treatment with a) $3 \% \mathrm{NaCl}$ (b) $10 \% \mathrm{Na}_{2} \mathrm{SO}_{4}$ (c) 1 $\mathrm{M} \mathrm{NaOH}$ d) $1 \mathrm{M} \mathrm{NaOH}+3 \% \mathrm{NaCl}$ e) $1 \mathrm{M} \mathrm{NaOH}+10 \% \mathrm{Na}_{2} \mathrm{SO}_{4}$ (f) $1 \mathrm{M} \mathrm{NaOH}+10 \% \mathrm{Na}_{2} \mathrm{SO}_{4}$ $+3 \% \mathrm{NaCl}$.

\section{DISCUSSION}

The SEM results show that little to no degradation occurs on the BF exposed to only the $\mathrm{NaCl}$ or the $\mathrm{Na}_{2} \mathrm{SO}_{4}$; small deposits of the chloride and sulfate salts were observed on the fibers.

All the fibers exposed to the alkaline $\mathrm{NaOH}$ solution showed degradation. This degradation is caused by the hydroxyl ions forming weak bonds with silicon atoms on the substrate surface, causing the original lattice bonds to weaken.

The addition of $\mathrm{NaCl}$ to the $\mathrm{NaOH}$ resulted in similar observations to the $\mathrm{NaOH}$ solution. However, when $\mathrm{Na}_{2} \mathrm{SO}_{4}$ was added to the $\mathrm{NaOH}$, the degradation of the fibers increased, such that the fibers are reduced to powder by the conclusion of the trial. It is hypothesised that this is due to the sulfate ions increasing the $\mathrm{pH}$ of the solution due to the hydration reaction. 


$$
\mathrm{SO}_{4}{ }^{2-}+\mathrm{H}_{2} \mathrm{O}<---->\mathrm{HSO}_{4}^{-}+\mathrm{OH}^{-} \text {(Hence release of more } \mathrm{OH}-\text { ions) }
$$

This was reflected by a lower $\mathrm{pH}$ in the $\mathrm{NaOH}+\mathrm{Na}_{2} \mathrm{SO}_{4}$ solution compared to the $\mathrm{NaOH}$ or $\mathrm{NaOH}+\mathrm{NaCl}$ solutions.

\section{CONCLUSION}

Neither chloride ions nor sulfate ions alone have any deleterious effect on the BF. However, in an alkaline environment equivalent to a $\mathrm{pH} 12.5$, severe degradation was observed. Degradation increased in an alkaline environment due to the presence of sulfate ions. The presence of chloride ions had little effect on the degradation in alkaline solutions, but did slightly reduce the effect when both chloride and sulfate ions were present.

The data indicates that the use of $\mathrm{BF}$ in concrete as fiber reinforcement is susceptible to degradation due to the alkaline nature of the concrete. Hence modification or treatment of basalt fibers before using in concrete is recommended.

\section{Acknowledgements}

The authors would like to acknowledge Mr. Pavel Ryjkov and other technical staff of concrete laboratory of RMIT for their support in conducting the experiment. The SEM analysis was done with the assistance of the RMIT Microscopy and Microanalysis Facility (RMMF) at RMIT University. Also, would like to acknowledge the Kemenny Vek Ltd., Dubna, Moscow, Russia for providing basalt fibers.

\section{References}

Bin, W., Cao, H., and Song, S., Degradation of basalt fiber and glass/epoxy resin composites in seawater, Corrosion Science, Vol. 53, 426-431, 2011.

Bo, X., Li, H. and Xian, G., Hydrothermal aging of basalt fiber reinforced epoxy composites, The 5th International Conference on FRP Composites in Civil Engineering, China, 2010.

Jongsung, S., Park, C., and Moon, D. Y., Characteristics of basalt fiber as a strengthening material for concrete structures, Composites: Part B Engineering, Vol. 36, 504-512, 2005.

Jung, T. H., and Subramanian, R. V., Alkali resistance enhancement of basalt fibers by hydrated zirconia films by the sol-gel process, Journal of Materials Research, Vol. 9-4, Apr 1994.

Militky, J., Zeisbergerova, J., and Kovacic, V., Chemical degradation of Basalt Fibers, 2003. Trovel, Inc., Retrieved from http://en.trovel.ru/u/file/chemical_degradation_of_basalt_fibers .doc.

Rabinovich, F. N., Stability of basalt fibers in a medium of hydrating cement, International Journal of Glass and Ceramics, Vol. 58, 11-12, 2001.

Van de Velde, K., Basalt fiber as reinforcement for a composite, Basaltex.com, 2001. Retrieved from www.basaltex.com/files/cms1/Basalt-Fibers-as-reinforcement-for-composites_Ugent .pdf.

Wang M., Chemical durability and mechanical properties of alkali-proof basalt fiber and its reinforced epoxy composites, Journal of Reinforced Plastics and Composites, SAGE, Vol. 27-4, 393, Beijing, China, Jan. 2008. 